\title{
Article \\ Genetic and Pharmacological Manipulations of Glyoxalase 1 Mediate Ethanol Withdrawal Seizure Susceptibility in Mice
}

\author{
Amanda M. Barkley-Levenson ${ }^{1, *}$, Amy Lee ${ }^{1}$ and Abraham A. Palmer ${ }^{1,2}$ \\ 1 Department of Psychiatry, University of California San Diego, 9500 Gilman Dr, La Jolla, CA 92093, USA; \\ aml107@health.ucsd.edu (A.L.); aapalmer@ucsd.edu (A.A.P.) \\ 2 Institute for Genomic Medicine, University of California San Diego, 9500 Gilman Dr, La Jolla, CA 92093, USA \\ * Correspondence: ambarkle@ucsd.edu; Tel.: +1-858-822-4035
}

check for updates

Citation: Barkley-Levenson, A.M.; Lee, A.; Palmer, A.A. Genetic and Pharmacological Manipulations of Glyoxalase 1 Mediate Ethanol Withdrawal Seizure Susceptibility in Mice. Brain Sci. 2021, 11, 127. https://doi.org/10.3390/ brainsci11010127

Academic Editor: Claudio D'Addario Received: 20 November 2020

Accepted: 15 January 2021

Published: 19 January 2021

Publisher's Note: MDPI stays neutral with regard to jurisdictional claims in published maps and institutional affiliations.

Copyright: (C) 2021 by the authors. Licensee MDPI, Basel, Switzerland. This article is an open access article distributed under the terms and conditions of the Creative Commons Attribution (CC BY) license (https:/ / creativecommons.org/licenses/by/ $4.0 /)$.

\begin{abstract}
Central nervous system (CNS) hyperexcitability is a clinically significant feature of acute ethanol withdrawal. There is evidence for a genetic contribution to withdrawal severity, but specific genetic risk factors have not been identified. The gene glyoxalase 1 (Glo1) has been previously implicated in ethanol consumption in mice, and GLO1 inhibition can attenuate drinking in mice and rats. Here, we investigated whether genetic and pharmacological manipulations of GLO1 activity can also mediate ethanol withdrawal seizure severity in mice. Mice from two transgenic lines overexpressing Glo1 on different genetic backgrounds (C57BL/6J (B6) and FVB/NJ (FVB)) were tested for handling-induced convulsions (HICs) as a measure of acute ethanol withdrawal. Following an injection of $4 \mathrm{~g} / \mathrm{kg}$ alcohol, both B6 and FVB mice overexpressing Glo1 showed increases in HICs compared to wild-type littermates, though only the FVB line showed a statistically significant difference. We also administered daily ethanol injections $(2 \mathrm{~g} / \mathrm{kg}+9 \mathrm{mg} / \mathrm{kg}$ 4-methylpyrazole) to wild-type B6 mice for 10 days and tested them for HICs on the 10th day following treatment with either a vehicle or a GLO1 inhibitor (S-bromobenzylglutathione cyclopentyl diester (pBBG)). Treatment with pBBG reduced HICs, although this effect was only statistically significant following two 10-day cycles of ethanol exposure and withdrawal. These results provide converging genetic and pharmacological evidence that GLO1 can mediate ethanol withdrawal seizure susceptibility.
\end{abstract}

Keywords: ethanol; withdrawal; genetics; handling induced convulsions; glyoxalase 1

\section{Introduction}

Alcohol (ethanol) withdrawal is a key feature of alcohol dependence and includes physiological and affective symptoms, such as tremors, nausea, vomiting, irritability, insomnia, and anxiety. Withdrawal symptoms are included in the diagnostic criteria for an alcohol use disorder [1], and withdrawal may be related to relapse risk, e.g., [2-4]. In severe cases, acute withdrawal can lead to serious consequences, such as delirium, seizures, or even death [5-7]. The determinants of ethanol withdrawal severity are not fully known, but there are likely multiple contributing factors, including drinking history, past withdrawal experience, co-occurring use of other drugs, structural brain lesions, and genetics [5,8]. Understanding the biological factors that confer risk for severe ethanol withdrawal may therefore lead to improved prevention and treatment options.

There is considerable evidence from both human and model organism studies for genetic contributions to ethanol withdrawal severity [9-13]. In humans, gene polymorphisms associated with many neurotransmitter systems have been explored in relation to ethanol withdrawal (for a review, see [8]). Several of these candidate genes and association studies have identified relationships between specific genetic variants and ethanol withdrawal severity [14-18]. However, large-scale human genetics studies have predominately focused on alcohol consumption and alcohol use disorder diagnoses rather than withdrawal severity. Animal models are a useful complementary tool for studying novel genetic contributions to ethanol-related traits, since animal models can isolate specific aspects 
of ethanol withdrawal, such as seizure susceptibility. The heritability of susceptibility to ethanol withdrawal seizures has been well-established in mouse models: inbred mouse strains and recombinant inbred panels show a high degree of phenotypic variation for this trait [11,19-21], and selective breeding has produced withdrawal-seizure-prone and resistant lines of mice $[10,22]$.

Here, we used a mouse model of ethanol withdrawal to investigate the role of glyoxalase 1 (GLO1) in withdrawal seizure severity. GLO1 is a ubiquitously expressed enzyme that metabolizes the glycolytic byproduct methylglyoxal (MG). We have previously shown that $\mathrm{MG}$ can act as a partial agonist at $\mathrm{GABA}_{\mathrm{A}}$ receptors and that the inhibition of GLO1 leads to increased levels of MG [23]. Genetic and pharmacological manipulations of the GLO1 system, as well as direct administration of MG, have been associated with changes in anxiety- and depression-like behaviors, ethanol consumption, and the seizure threshold. Specifically, decreased anxiety-like behavior [23,24], decreased depression-like behavior $[25,26]$, decreased ethanol consumption $[27,28]$, and decreased susceptibility to pilocarpine- and picrotoxin-induced seizures [29] have all been seen following GLO1 inhibitor treatment. Some of these effects are also produced by the genetic knockdown of Glo1 or direct MG administration. In contrast, Glo1 overexpression produces the opposite effects (i.e., increased anxiety-like behavior and ethanol consumption) $[23,25,27]$. Furthermore, Glo1-overexpressing mice show increased GLO1 enzymatic activity and decreased whole-brain MG levels, whereas wild-type mice treated with a GLO1 inhibitor show the opposite effects [23].

We hypothesize that modulating GLO1 activity could impact ethanol withdrawal, potentially through downstream effects on MG levels and subsequent GABAergic activation. Significant changes in GABAergic signaling following chronic ethanol use are believed to underlie, in part, the central nervous system hyperexcitability seen in ethanol withdrawal (e.g., [30-32]). In the present studies, we examined whether the overexpression of Glo1 could potentiate ethanol withdrawal seizure severity and whether the pharmacological manipulation of GLO1 activity by treatment with a GLO1 inhibitor could attenuate ethanol withdrawal seizure severity in mice.

\section{Materials and Methods}

\subsection{Animals and Husbandry}

All Glo1 transgenic mice used in experiments 1 and 2 were bred in-house. Generation of the Glo1 transgenic mice via the insertion of a BAC transgene has been previously described [23]. The Glo1 transgenic lines were maintained by breeding male mice that were heterozygous for the Glo1 overexpression with wild-type female mice (B6 or FVB depending on the line). The resulting heterozygous and wild-type littermates were used as experimental animals. For experiment 3, wild-type B6 mice were purchased from the Jackson Laboratory (Bar Harbor, ME, USA). For all experiments, mice were housed 2-5 per cage on wood chip bedding and food (Envigo 8604, Indianapolis, IN, USA) and water were provided ad libitum. Mice were maintained on a $12 \mathrm{~h} / 12 \mathrm{~h}$ light/dark cycle with lights on at 06:00. Behavioral testing was conducted during the light phase. All procedures were approved by the University of California San Diego Institutional Animal Care and Use Committee (\#S15226) and were conducted in accordance with the NIH Guidelines for the Care and Use of Laboratory Animals.

\subsection{Handling-Induced Convulsions}

Handling-induced convulsions (HICs) are used to assess the susceptibility to ethanol withdrawal seizures and serve as a measure of central nervous system (CNS) hyperexcitability. We used the seven-point scale developed by Crabbe and colleagues (e.g., [33]) based on the original procedure by Goldstein and Pal [34]. Briefly, mice were lifted by the tail and observed for convulsion signs. If lifting alone did not produce a convulsion, the mouse was gently spun in a 360-degree arc. Scores ranged from 0 (no convulsion) to 7 (severe and sometimes lethal seizure due to environmental stimuli). Baseline HIC assessments were 
made prior to ethanol administration. In experiments 1 and 3, HICs were assessed hourly from $2-10 \mathrm{~h}$ after the final ethanol injection. In experiment 2 , HICs were assessed only during peak withdrawal (6-8 $\mathrm{h}$ after the final ethanol injection). In all experiments, a final HIC measurement was taken $24 \mathrm{~h}$ into the withdrawal. Experimenters were blinded to the genotype and treatment for all HIC assessments, and the same experimenter performed all HIC assessments within a given experiment. A withdrawal severity score was calculated by summing the total post-ethanol HIC scores to find the area under the curve (AUC) of the HIC time course in experiments 1 and 2, and the HIC scores from hours 4-10 in experiment $3[35,36]$. The peak HIC score was determined by averaging the highest HIC score recorded for each animal with the HIC scores from the hourly assessments immediately preceding and following the time of the maximum score [21]. In instances where there were multiple time points with the same maximum score, the earliest occurrence was used. Latency to the peak HIC score was the time at which the highest score first occurred. Animals that did not show any HICs were excluded from the latency analyses.

\subsection{Drugs}

The GLO1 inhibitor S-bromobenzylglutathione cyclopentyl diester (pBBG) was synthesized in the laboratory of Alexander Arnold at the University of Wisconsin-Milwaukee, as previously described [27]. The dose of $25 \mathrm{mg} / \mathrm{kg}$ was chosen because it was believed to be an intermediate dose in the behaviorally active range; $12.5 \mathrm{mg} / \mathrm{kg}$ and $50 \mathrm{mg} / \mathrm{kg}$ doses were shown to reduce ethanol drinking and anxiety-like behavior, respectively, in previous studies [23,27], and $25 \mathrm{mg} / \mathrm{kg}$ can attenuate withdrawal-associated escalation of ethanol drinking in dependent rats [28]. pBBG was dissolved in a vehicle $(8 \% \mathrm{DMSO} / 18 \%$ Tween80/saline [Sigma-Aldrich, St. Louis, MO, USA]) and administered via intraperitoneal injection (i.p.;injection volume $0.01 \mathrm{~mL} / \mathrm{g}$ ). Ethanol (Deacon Laboratories Inc., King of Prussia, PA, USA) was mixed in saline $(20 \% v / v)$ and administered i.p. at a dose of $4 \mathrm{~g} / \mathrm{kg}$ in experiments 1 and 2. In experiment 3 , the alcohol dehydrogenase inhibitor 4-methylpyrazole ( $9 \mathrm{mg} / \mathrm{kg}$; Sigma-Aldrich, St. Louis, MO, USA) was dissolved in $20 \%$ ethanol solution or physiological saline such that animals received only a single injection for both the ethanol or saline and pyrazole administration.

\subsection{Experiment 1: Acute Ethanol Withdrawal in Glo1 Transgenic Mice on a B6 Background}

Male and female mice from the B6 background Glo1 transgenic line were used in this experiment ( $n=4$ /sex/genotype). All animals were between 59-153 days at the start of testing. Mice were weighed, assessed for a baseline HIC score, and then injected i.p. with $4 \mathrm{~g} / \mathrm{kg}$ ethanol and returned to the home cage. Starting two hours after the ethanol injection, mice were assessed hourly for HICs with the final HIC assessment made at $10 \mathrm{~h}$ after the injection. The following morning, $24 \mathrm{~h}$ after the previous injection, the final HIC assessment was made.

\subsection{Experiment 2: Acute Ethanol Withdrawal in Glo1 Transgenic Mice on an FVB Background}

Because the B6 background mice in experiment 1 showed limited ethanol withdrawal seizure susceptibility, we sought to extend our studies to include FVB Glo1 transgenic mice because FVB mice have higher HIC scores during ethanol withdrawal than B6 mice [21]. Peak withdrawal scores were seen from 6-8 $\mathrm{h}$ after the injection in experiment 1 ; therefore, in experiment 2, we limited HIC assessments to this peak withdrawal window. Only females were used for experiment 2 due to animal availability ( $n=9-12$ /genotype); all mice were 241-287 days of age at testing. As in experiment 1, mice were weighed, given a baseline HIC assessment, and then injected with $4 \mathrm{~g} / \mathrm{kg}$ ethanol and returned to their home cages. HICs were assessed at 6, 7, and $8 \mathrm{~h}$ after the injection and again the next morning at $24 \mathrm{~h}$ after the injection. 


\subsection{Experiment 3: GLO1 Inhibitor Effects on Chronic Ethanol Withdrawal}

To assess whether pharmacological manipulations of GLO1 activity could also influence ethanol withdrawal, we tested whether the GLO1 inhibitor pBBG could attenuate withdrawal seizure severity following chronic ethanol exposure. Importantly, GLO1 inhibition should produce effects that are opposite to those produced by Glo1 overexpression. Male B6 mice were used for this experiment ( $n=11-13 /$ treatment group); all animals were 75-77 days of age at the start of testing. Male B6 animals were chosen because the majority of our studies examining GLO1 inhibitor effects on behavior and effective dose ranges have used male B6 mice. Because wild-type B6 animals showed limited withdrawal seizure susceptibility following acute ethanol injection in experiment 1 , we used a chronic ethanol dosing model in this experiment to induce dependence. Specifically, we used a 10-day ethanol injection paradigm adapted from Perez and De Biasi [37] that has been previously shown to produce somatic and affective signs of withdrawal in male B6 mice. The mice received a daily injection of either $2 \mathrm{~g} / \mathrm{kg}$ ethanol (withdrawal group) or $0.9 \%$ saline (non-withdrawal control group) with $9 \mathrm{mg} / \mathrm{kg}$ 4-methylpyrazole for 10 days.

Baseline HICs were assessed before the first injection was given. On day 10, the HIC time course was assessed starting $2 \mathrm{hr}$ after the final injection and again hourly until $10 \mathrm{~h}$ post injection. At $3.5 \mathrm{~h}$ after the final ethanol injection, mice received an i.p. injection of either $25 \mathrm{mg} / \mathrm{kg}$ pBBG or a vehicle. This pretreatment time was chosen to give sufficient time for GLO1 inhibition to lead to increased MG levels during peak withdrawal. A final HIC assessment was made the next day at $24 \mathrm{~h}$ after the final ethanol injection.

To determine whether the effectiveness of pBBG changed with increased ethanol exposure, and due to the low levels of withdrawal seizure susceptibility seen following the initial ethanol exposure, we repeated the same procedure for a second cycle of ethanol exposure and withdrawal. Following the first 10-day ethanol withdrawal cycle, mice were allowed to remain undisturbed for 6 weeks in their home cages before we repeated the 10-day procedure described above. All mice received the same drug treatment and the same experimental procedures were used in both ethanol withdrawal cycles, including a re-baselining HIC assessment before the start of the second ethanol exposure period.

\subsection{Statistical Analyses}

Data are expressed as mean \pm SEM. All statistical analyses were performed using SPSS (version 27; IBM Corp, Armonk, NY, USA). The HIC time course data were analyzed using mixed-model analysis of variance (ANOVA) with a repeated measure of time-point and between-subject factors of genotype, treatment group, and/or sex, as relevant for the given experiment. A Huynh-Feldt correction for violations of sphericity was used for repeated measures analyses. The HIC AUC, peak HIC score, and latency to peak HIC score data were analyzed using one- or two-way ANOVA. Significance was set at $\alpha=0.05$ for all tests. Individual-level data can be found in the supplement in Table S1 (total number of mice per maximum HIC score in each experiment).

\section{Results}

\subsection{Experiment 1: Acute Ethanol Withdrawal in Glo1 Transgenic Mice on a B6 Background}

The withdrawal HIC time course (Figure 1a) was analyzed using a mixed-model ANOVA with a repeated measure of time and between-subject factors of genotype and sex. There were statistical trends toward the main effects of time $\left(F_{5.83,70}=1.95, p=0.086\right)$ and genotype $\left(F_{1,12}=4.2, p=0.063\right)$, and a main effect of $\operatorname{sex}\left(F_{1,14}=4.2, p=0.022\right.$, males $>$ females). There were no significant interactions between any factors ( $p>0.1$ for all). The HIC time course, AUC, and peak HIC scores for males and females (collapsed on genotype) are shown in Supplementary Figure S1. The data in Figure 1 are shown broken down by genotype to allow for comparison with the results of experiment 2 . 
a)

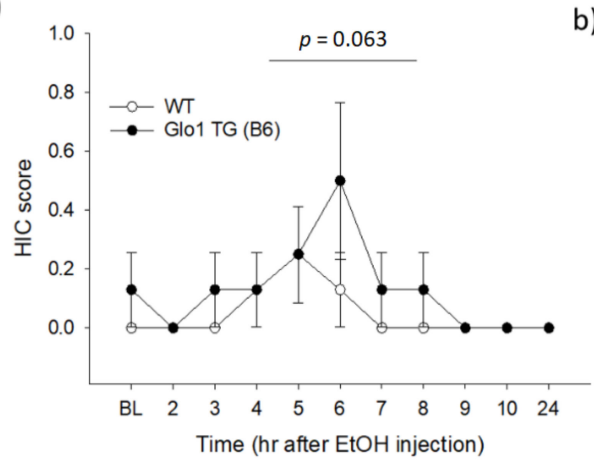

b)

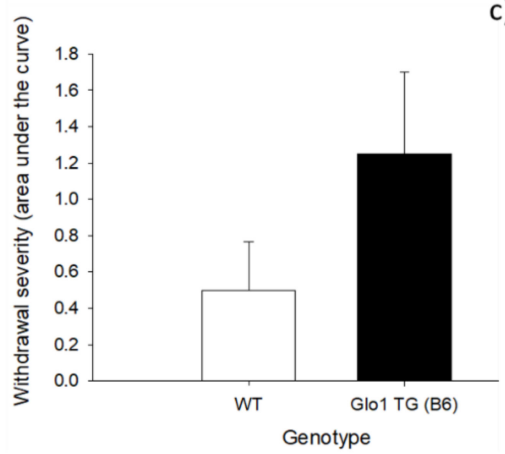

c)

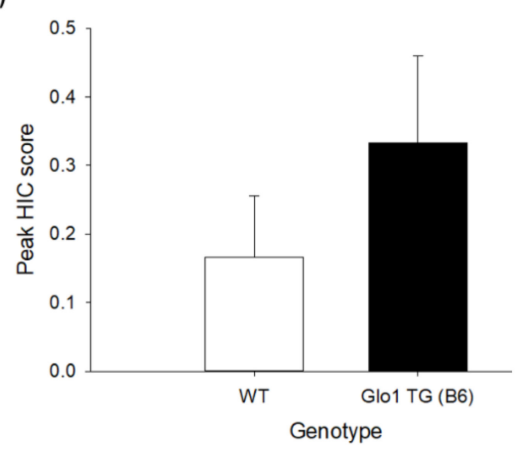

Figure 1. Acute ethanol withdrawal as assessed using handling-induced convulsions (HICs) in wild-type (WT) and Glo1overexpressing (TG) mice on a C57BL/6J (B6) genetic background. Panel (a) shows the time course of the withdrawal, with baseline HIC measurements made immediately before the ethanol injection. There was a statistical trend of overexpressing mice trending toward higher HIC scores across the time course. Panel (b) shows the cumulative HIC scores (area under the curve (AUC)) for each genotype. Panel (c) shows the peak HIC score for each genotype. Genotype differences for both the AUC and peak HIC scores were not statistically significant. $n=8 /$ genotype.

To determine the differences in overall withdrawal severity, we analyzed the area under the HIC curve. The HIC AUC did not differ significantly between the genotypes $\left(F_{1,12}=2.35, p=0.151\right.$; Figure $\left.1 b\right)$, though there was a statistical trend toward a main effect of $\operatorname{sex}\left(F_{1,12}=4.17, p=0.064\right.$; Figure $\left.S 1 b\right)$. There were no main effects of either genotype $\left(F_{1,12}=1.26, p=0.283\right.$; Figure $\left.1 c\right)$ or $\operatorname{sex}\left(F_{1,12}=2.84, p=0.118\right.$; Figure S1c) for the peak HIC score (Figure 1c). The latency to peak HIC also showed no main effects of sex or genotype $\left(F_{1,5} \leq 0.091, p \geq 0.771\right.$, data not shown). There were no significant genotype $\times$ sex interactions for any measure $(p>0.1$ for all $)$.

\subsection{Experiment 2: Acute Ethanol Withdrawal in Glo1 Transgenic Mice on an FVB Background}

The withdrawal HIC time course (Figure 2a) was analyzed using a mixed-model ANOVA with a repeated measure of time and a between-subjects factor of genotype. There were main effects of time $\left(F_{3 \cdot 88,73 \cdot 68}=37.02, p<0.001\right)$ and genotype $\left(F_{1,19}=6.32, p=0.021\right)$, but no significant time $\times$ genotype interaction. Analysis of the HIC AUC (Figure $2 b$ ) and peak HIC score (Figure 2c) showed that transgenic mice displayed significantly greater withdrawal severity $\left(F_{1,19}=5.24, p=0.034\right)$ and higher peak HIC scores $\left(F_{1,19}=4.99, p=0.038\right)$ than wild-type mice. The latency to peak HIC did not differ between the genotypes $\left(F_{1,18}=0.015, p=0.903\right.$, data not shown $)$.
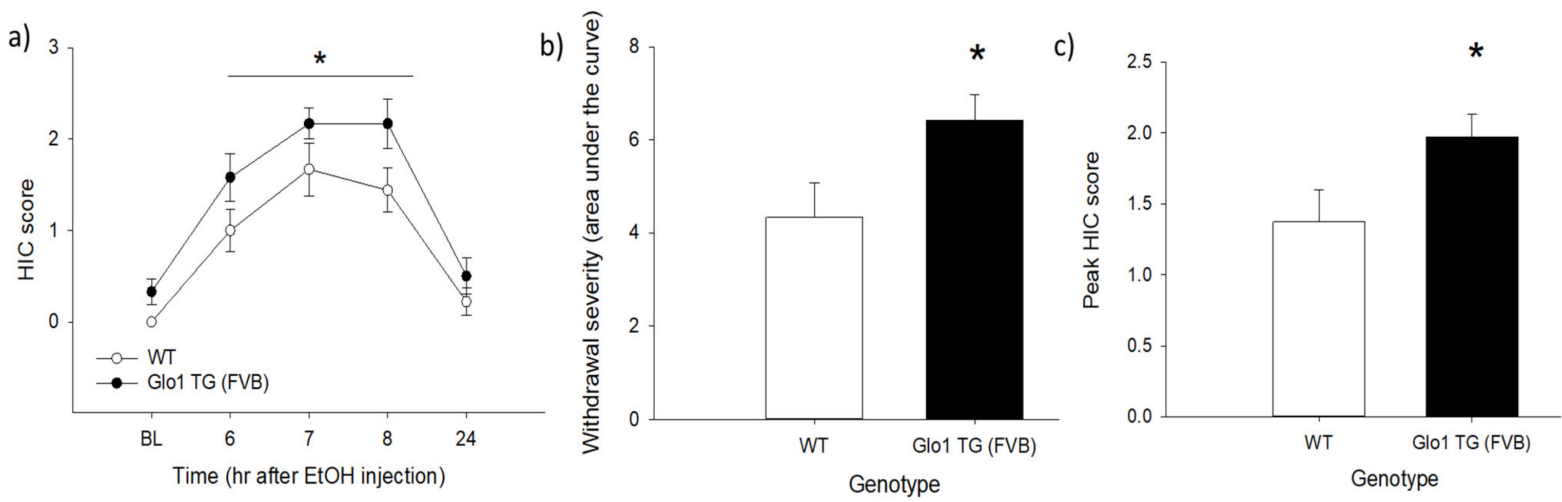

Figure 2. Acute ethanol withdrawal as assessed using HICs in wild-type (WT) and Glo1-overexpressing (TG) mice on an FVB/NJ (FVB) genetic background. Panel (a) shows the time course of withdrawal, with baseline HIC measurements made immediately before the ethanol injection. There was a main effect of genotype, with Glo1-overexpressing mice having higher HIC scores across the time course that WT mice. Glo1-overexpressing mice also showed greater cumulative seizure susceptibility (area under the curve (AUC), panel (b)), and higher peak HIC scores than WT littermates (panel (c)). * indicates $p<0.05 . n=9-12 /$ genotype. 


\subsection{Experiment 3: GLO1 Inhibitor Effects on Chronic Ethanol Withdrawal}

Figure 3 shows the withdrawal HIC measures after one or two cycles of chronic ethanol treatment. No animals in the non-withdrawal control groups (saline-vehicle and salinepBBG) showed any seizure activity (0 scores for all animals at all time points); therefore, only the data from the withdrawal group are reported here. Analysis with mixed-model ANOVA of the HIC time course found a main effect of time following a single ethanol cycle (Figure 3a: $F_{3 \cdot 19,70 \cdot 06}=3.24, p=0.025$ ) and a trend toward a main effect of genotype $\left(F_{1,22}=3.28, p=0.084\right)$, but it did not reach the level of statistical significance. There was also no significant treatment $\times$ time interaction $(p>0.1)$. After two cycles of ethanol exposure, there were main effects of both time and treatment (Figure $3 \mathrm{~b}: F_{2 \cdot 77,61 \cdot 02}=4.44$, $p=0.008$ and $F_{1,22}=5.38, p=0.03$, respectively). The time $\times$ treatment interaction was not statistically significant $\left(F_{2} \cdot 77,61 \cdot 02=2.28, p=0.093\right)$.

The AUC was calculated for hours 4-10, as this was the time range when the GLO1 inhibitor treatment was expected to have an effect. Analysis of the area under the HIC curve showed that following one cycle of ethanol, there was a trend toward a lower HIC AUC in the inhibitor-treated group compared to the vehicle group (Figure 3c: $F_{1,22}=3.38$, $p=0.079)$, but it was not statistically significant. There was also no significant main effect of the treatment on the peak HIC score (Figure $3 \mathrm{~d} ; F_{1,22}=3.28, p=0.084$ ) or latency to peak HIC $\left(F_{1,6}=0.19, p=0.68\right.$, data not shown) after one cycle of ethanol. In contrast, after two cycles of ethanol exposure, there were significant effects of the treatment on both the HIC AUC (Figure 3e) and peak HIC score (Figure 3f), with GLO1 inhibition significantly reducing both measures $\left(F_{1,22}=5.38, p=0.03\right.$ for both). The latency to peak HIC again did not differ between the groups $\left(F_{1,6}=0.56, p=0.482\right.$, data not shown).

Because of the low overall withdrawal scores in the vehicle-treated animals (HIC scores ranged from $0-1$ ) and the potential of a floor effect, one-sample $t$-tests (two-tailed) were used to determine whether the HIC AUC in each cycle was significantly different from 0 (AUC for non-withdrawal control groups). The HIC AUC was significantly different from 0 following both one and two cycles of ethanol treatment (cycle 1: $t(12)=2.84$, $p=0.015$; cycle 2: $t(12)=2.99, p=0.011$; Bonferroni corrected $\alpha=0.025)$, indicating that there was a measurable withdrawal in the vehicle-treated group from which reductions due to the PBBG treatment could be assessed.

a)

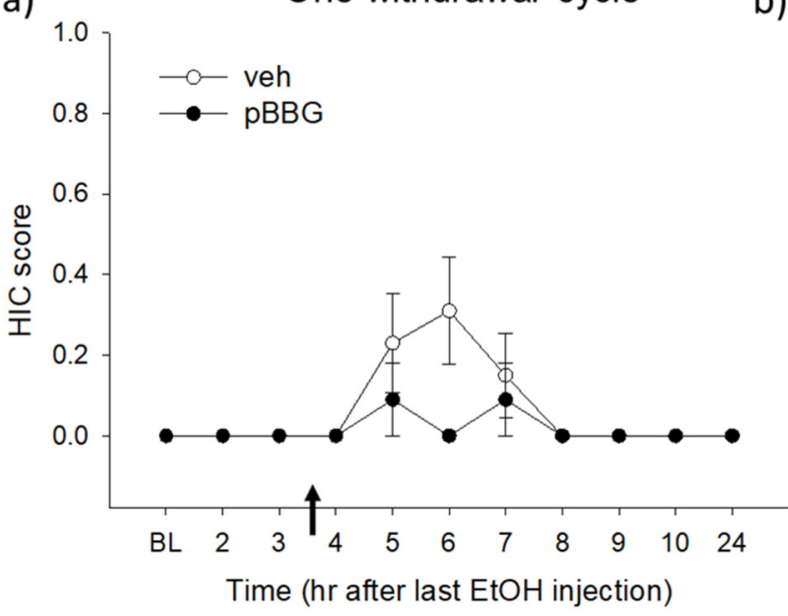

b)

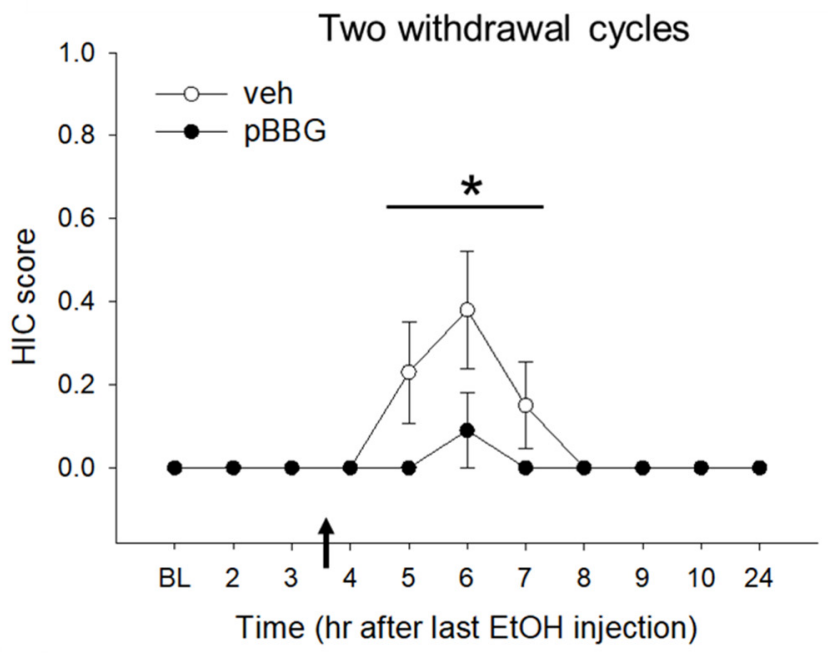

Figure 3. Cont. 
c)

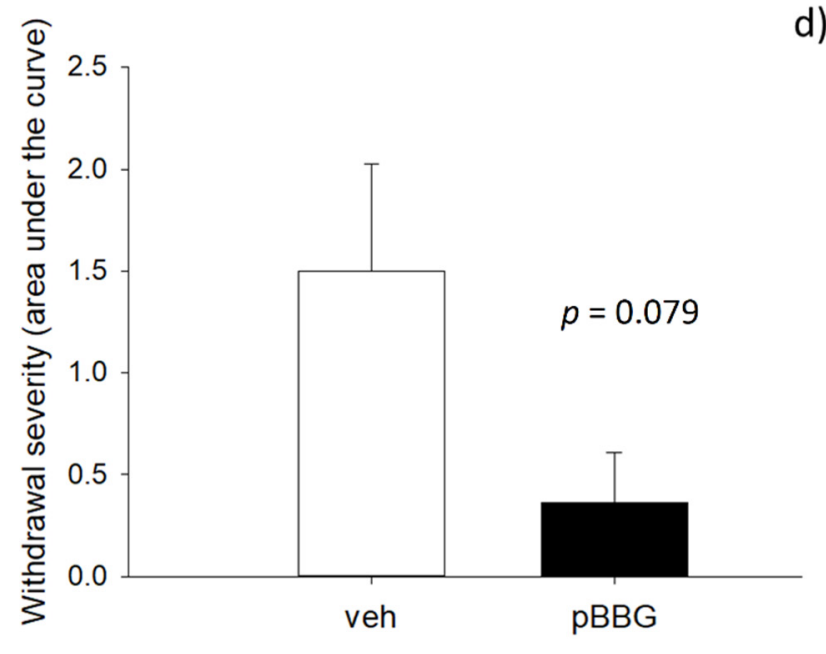

e)

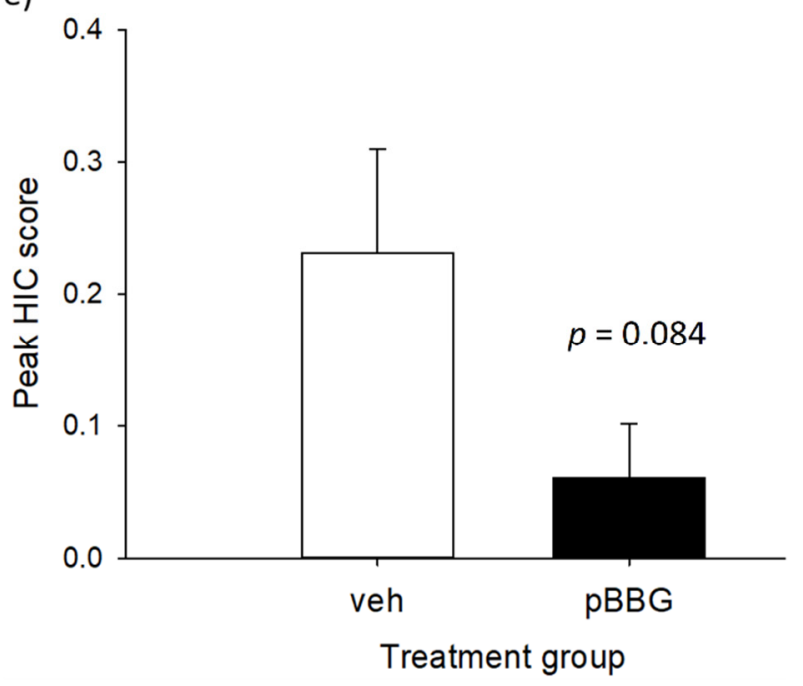

d)
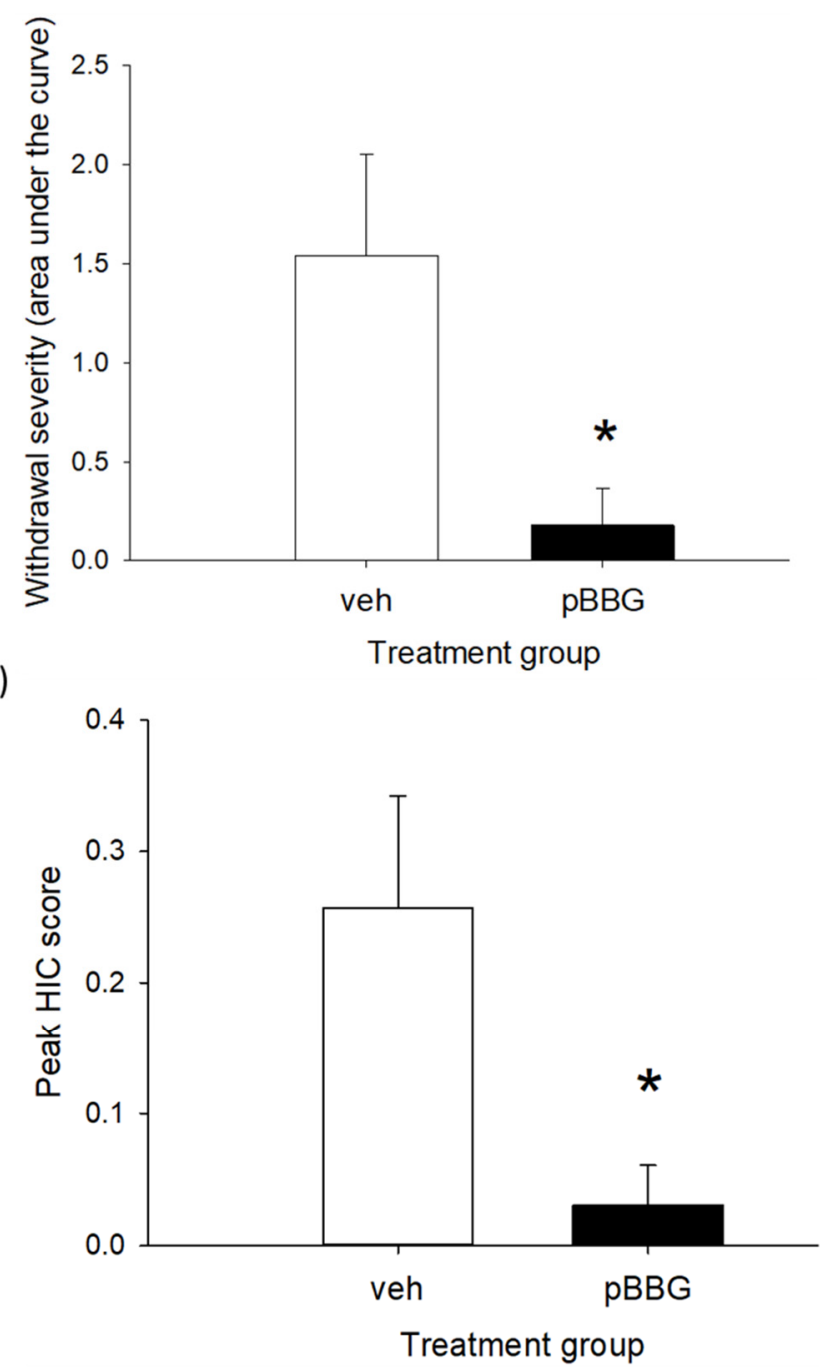

Figure 3. HIC time courses (a,b), area under the HIC curve (AUC) from hours 4-10 (c,d), and peak HIC scores (e,f) after one (left column) and two (right column) withdrawal cycles. Baseline HIC measurements were made before the start of each 10-day ethanol exposure period. Injections of GLO1 inhibitor (pBBG, $25 \mathrm{mg} / \mathrm{kg}$ ) or the vehicle (veh) were given $3.5 \mathrm{~h}$ after the final ethanol injection (indicated by arrows). ${ }^{*}$ indicates a statistically significant difference from the vehicle-treated mice $(p<0.05) . n=11-13 /$ treatment group.

\section{Discussion}

In these experiments, we showed that the overexpression of the gene Glo1 can produce increased ethanol withdrawal severity, as assessed using HICs. Furthermore, the treatment of wild-type animals with a GLO1 inhibitor had the opposite effect, namely, attenuating ethanol withdrawal seizure severity in mice undergoing a chronic ethanol exposure procedure. Taken together, these results provide evidence that GLO1 activity modulated CNS hyperexcitability during ethanol withdrawal in mice.

Analysis of the HIC time course in experiment 1 showed a weak trend toward increased HIC scores in mice overexpressing Glo1 on a B6 background, but this difference did not reach the threshold for statistical significance. In experiment 2, however, overexpression of Glo1 on an FVB background was found to significantly increase both the HIC AUC and peak HIC score. B6 mice have been previously shown to be largely resistant to ethanol withdrawal seizures [20,38-40] and this is consistent with our findings here. Most animals in experiment 1 had low or no seizure activity and the observed HIC scores only ranged from $0-2$, meaning that the most severe seizure observed was a tonic convulsion after spinning (Table S1). In contrast, mice in experiment 2 showed much greater seizure 
activity, with HIC scores ranging from 0-4 (a score of 4 corresponds to a tonic convulsion when the mouse is lifted by the tail, with no spin required to elicit the convulsion). This difference in withdrawal severity between the two transgenic lines suggests that the genetic background may be an important mediator of Glo1's effects on ethanol withdrawal. The two transgenic lines also differed in their number of copies of Glo1 (the B6 line has 17 copies, whereas the FVB line has 48 copies), and this could have also contributed to the differences in withdrawal potentiation between the lines.

In experiment 3, we found that pharmacological inhibition of GLO1 produced the opposite effects to the genetic overexpression of Glo1 (i.e., reduced HICs during ethanol withdrawal). Interestingly, treatment with the GLO1 inhibitor pBBG only produced a trend toward an effect following one cycle of ethanol exposure but led to significant decreases in HIC severity after two cycles. This suggests that GLO1 inhibition may be more effective in animals with a greater dependence history. This is consistent with previous findings, where pBBG was more effective at reducing ethanol drinking in dependent rats compared to non-dependent rats [28]. In the present study, there was no significant ethanol cycle $\times$ treatment group interaction for either the AUC or peak HIC score (data not shown); therefore, we cannot state conclusively what may be driving the increased efficacy seen with two ethanol withdrawal cycles. There is considerable evidence that ethanol withdrawal severity increases with repeated withdrawal experience ("kindling" effect) (e.g., [41-43]). It could be that withdrawal severity increased modestly with the repeated ethanol cycles, thereby eliminating any floor effect and making it easier to see a statistically significant reduction in seizure activity following the pBBG treatment. Alternatively, it is possible that $\mathrm{pBBG}$ is more effective in animals with a greater ethanol history due to the subsequent neuroadaptations or a combination of these factors.

To our knowledge, these studies are the first examination of GLO1 activity as a potential mediator of ethanol withdrawal severity. Previous work in the lab has demonstrated that naïve Glo1 transgenic mice have increased GLO1 enzymatic activity and decreased brain MG levels compared to wild-type littermates [23], though it is unknown whether this genotypic difference persists in ethanol-treated animals. MG treatment can reduce both the severity and duration of pharmacologically induced seizures, as well as electroencephalogram measures of seizure activity in mice [29]. Electrophysiological studies have also shown that $\mathrm{MG}$ can act as an agonist at $\mathrm{GABA}_{\mathrm{A}}$ receptors [23]. Chronic ethanol produces significant neuroadaptations, particularly in the GABA and glutamate systems, which underlie some of the symptoms of ethanol withdrawal (e.g., [30,44-46]). Therefore, one possible explanation for the effects of GLO1 manipulations on ethanol withdrawal seizures may be subsequent downstream changes in $\mathrm{MG}$ levels and activity at $\mathrm{GABA}_{\mathrm{A}}$ receptors. However, it should be noted that we did not directly measure MG levels during withdrawal in these studies, and therefore these possibilities are speculative. The direct measurement of MG brain levels during withdrawal will be an important step for determining how the glyoxalase system may specifically be altered by ethanol treatment and subsequent withdrawal. GLO1's effects on negative affective changes during protracted abstinence should also be examined, since many of these changes (e.g., increased anxiety- and depression-like behavior) have been seen with genetic and pharmacological manipulation of GLO1 activity in non-dependent mice [23-25].

There are some limitations of the present studies that should be noted. First, potential sex differences were only directly examined in experiment 1 , and the number of animals per sex per genotype likely provided limited power for identifying interactions with sex. However, we did see significant and consistent effects of GLO1 manipulations in both male and female animals in experiments 2 and 3, even though the sexes were not directly compared in these experiments. Mice in experiment 2 were also older on average than mice in the other two experiments, and potential age effects cannot be ruled out with the current experimental design. However, the parallel effects seen with the genetic overexpression of Glo1 and pharmacological inhibition in two different inbred strains, as well as the consistency in findings in both acute and chronic withdrawal models, suggest that the 
role of GLO1 in ethanol withdrawal severity generalizes across multiple populations and conditions. Additionally, although GLO1 inhibition reduced HICs, it did not return animals completely to the baseline levels. Testing a wider range of pBBG doses could help to determine whether there is an optimal dose that can fully eliminate withdrawal seizures. Finally, the overall level of withdrawal severity seen in experiments 1 and 3 was low, likely due to the use of B6 mice, and future studies in this genotype might benefit from a more extensive ethanol exposure method to induce greater dependence (e.g., chronic-intermittent ethanol vapor exposure).

In conclusion, we provided converging genetic and pharmacological evidence that GLO1 activity mediates ethanol withdrawal seizure susceptibility. In mice, the overexpression of Glo1 contributes to increased withdrawal seizure severity and the inhibition of GLO1 attenuates withdrawal seizure severity. GLO1 inhibition could therefore potentially be a useful strategy for the treatment of neural hyperexcitability during acute withdrawal. Further studies will be needed to determine how the glyoxalase system is altered by chronic ethanol exposure and whether GLO1 inhibitors may have utility for treating the negative affective changes seen during protracted abstinence.

Supplementary Materials: The following are available online at https:/ / www.mdpi.com/2076-342 5/11/1/127/s1, Table S1: Number of animals per maximum handling-induced convulsion (HIC) score for each experiment, Figure S1: Acute ethanol withdrawal measures for male and female mice from experiment 1 collapsed on genotype.

Author Contributions: Conceptualization, A.M.B.-L., A.L. and A.A.P.; formal analysis, A.M.B.-L. and A.L.; funding acquisition, A.A.P.; investigation, A.M.B.-L. and A.L.; project administration, A.M.B.-L.; supervision, A.A.P.; writing—original draft, A.M.B.-L.; writing—review and editing, A.M.B.-L., A.L. and A.A.P. All authors approved the final version of the manuscript for submission. All authors have read and agreed to the published version of the manuscript.

Funding: This work was supported by National Institutes of Health (NIH) grant R01 AA026281. A.M.B.-L. was supported by NIH grants F32 AA025515 and K99 AA07835.

Institutional Review Board Statement: These studies were approved by the University of California San Diego Institutional Animal Care and Use Committee (\#S15226, approval date: 9/20/2018) and were conducted in accordance with the NIH Guidelines for the Care and Use of Laboratory Animals.

Data Availability Statement: Data are available from the corresponding author upon request.

Conflicts of Interest: The authors declare no conflict of interest.

\section{References}

1. American Psychiatric Association. Diagnostic and Statistical Manual of Mental Disorders, 5th ed.; (DSM-5); American Psychiatric Association: Washington, DC, USA, 2013; p. 5.

2. Becker, H.C. Alcohol Dependence, Withdrawal, and Relapse. Neurobiol. Alcohol Depend. 2014, 31, 377-410. [CrossRef]

3. Breese, G.R.; Sinha, R.; Heilig, M. Chronic alcohol neuroadaptation and stress contribute to susceptibility for alcohol craving and relapse. Pharm. Ther. 2011, 129, 149-171. [CrossRef] [PubMed]

4. Heilig, M.; Egli, M.; Crabbe, J.C.; Becker, H.C. Acute withdrawal, protracted abstinence and negative affect in alcoholism: Are they linked? Addict. Biol. 2010, 15, 169-184. [CrossRef] [PubMed]

5. Jesse, S.; Bråthen, G.; Ferrara, M.; Keindl, M.; Ben-Menachem, E.; Tanasescu, R.; Brodtkorb, E.; Hillbom, M.; Leone, M.; Ludolph, A. Alcohol withdrawal syndrome: Mechanisms, manifestations, and management. Acta Neurol. Scand. 2017, 135, 4-16. [CrossRef]

6. McKeon, A.; Frye, M.A.; Delanty, N. The alcohol withdrawal syndrome. J. Neurol. Neurosurg. Psychiatry 2008, 79, 854-862. [CrossRef]

7. Saitz, R. Introduction to alcohol withdrawal. Alcohol Health Res. World 1998, 22, 5-12.

8. Schmidt, L.; Sander, T. Genetics of alcohol withdrawal. Eur. Psychiatry 2000, 15, 135-139. [CrossRef]

9. Kendler, K.S.; Aggen, S.H.; Prescott, C.A.; Crabbe, J.; Neale, M.C. Evidence for multiple genetic factors underlying the DSM-IV criteria for alcohol dependence. Mol. Psychiatry 2011, 17, 1306-1315. [CrossRef]

10. Kosobud, A.; Crabbe, J.C. Ethanol withdrawal in mice bred to be genetically prone or resistant to ethanol with-drawal seizures. J. Pharmacol. Exp. Ther. 1986, 238, 170-177.

11. Metten, P.; Crabbe, J.C. Alcohol withdrawal severity in inbred mouse (Mus musculus) strains. Behav. Neurosci. 2005, 119, 911-925. [CrossRef] 
12. Fehr, C.; Shirley, R.L.; Metten, P.; Kosobud, A.E.K.; Belknap, J.K.; Crabbe, J.C.; Buck, K.J. Potential pleiotropic effects of Mpdz on vulnerability to seizures. GenesBrain Behav. 2004, 3, 8-19. [CrossRef] [PubMed]

13. Scott, L.L.; Davis, S.J.; Yen, R.C.; Ordemann, G.J.; Nordquist, S.K.; Bannai, D.; Pierce, J.T. Behavioral deficits following withdrawal from chronic ethanol are influenced by SLO channel function in caenorhabditis elegans. Genetics 2017, 206, 1445-1458. [CrossRef] [PubMed]

14. Dutta, N.; Helton, S.G.; Schwandt, M.; Zhu, X.; Momenan, R.; Lohoff, F.W. Genetic Variation in the vesicular monoamine transporter 1 (VMAT1/SLC18A1) gene and alcohol withdrawal severity. Alcohol. Clin. Exp. Res. 2016, 40, 474-481. [CrossRef] [PubMed]

15. Grzywacz, A.; Jasiewicz, A.; Małecka, I.; Suchanecka, A.; Grochans, E.; Karakiewicz, B.; Samochowiec, A.; Bieńkowski, P.; Samochowiec, J. Influence of DRD2 and ANKK1 polymorphisms on the manifestation of withdrawal syndrome symptoms in alcohol addiction. Pharm. Rep. PR 2012, 64, 1126-1134. [CrossRef]

16. Huang, M.-C.; Schwandt, M.L.; Chester, J.A.; Kirchhoff, A.M.; Kao, C.-F.; Liang, T.; Tapocik, J.D.; Ramchandani, V.A.; George, D.T.; Hodgkinson, C.A.; et al. FKBP5 moderates alcohol withdrawal severity: Human genetic association and functional validation in knockout mice. Neuropsychopharmacology 2014, 39, 2029-2038. [CrossRef]

17. Sander, T.; Harms, H.; Podschus, J.; Finckh, U.; Nickel, B.; Rolfs, A.; Rommelspacher, H.; Schmidt, L.G. Allelic association of a dopamine transporter gene polymorphism in alcohol dependence with withdrawal seizures or delirium. Biol. Psychiatry 1997, 41, 299-304. [CrossRef]

18. Smith, A.H.; Ovesen, P.L.; Skeldal, S.; Yeo, S.; Jensen, K.P.; Olsen, D.; DiazGranados, N.; Zhao, H.; Farrer, L.A.; Goldman, D.; et al Risk locus identification ties alcohol withdrawal symptoms to SORCS2. Alcohol. Clin. Exp. Res. 2018, 42, 2337-2348. [CrossRef]

19. Crabbe, J.C. Provisional mapping of quantitative trait loci for chronic ethanol withdrawal severity in BXD recombi-nant inbred mice. J. Pharmacol. Exp. Ther. 1998, 286, 263-271.

20. Metten, P.; Crabbe, J.C. Common genetic determinants of severity of acute withdrawal from ethanol, pentobarbital and diazepam in inbred mice. Behav. Pharm. 1994, 5, 533-547. [CrossRef]

21. Metten, P.; Sorensen, M.L.; Cameron, A.J.; Yu, C.-H.; Crabbe, J.C. Withdrawal severity after chronic intermittent ethanol in inbred mouse strains. Alcohol. Clin. Exp. Res. 2010, 34, 1552-1564. [CrossRef]

22. Crabbe, J.C.; Kosobud, A.; Young, E.R. Genetic selection for ethanol withdrawal severity: Differences in replicate mouse lines. Life Sci. 1983, 33, 955-962. [CrossRef]

23. Distler, M.G.; Plant, L.D.; Sokoloff, G.; Hawk, A.J.; Aneas, I.; Wuenschell, G.E.; Termini, J.; Meredith, S.C.; Nobrega, M.A.; Palmer, A.A. Glyoxalase 1 increases anxiety by reducing GABAA receptor agonist methylglyoxal. J. Clin. Investig. 2012, 122, $2306-2315$. [CrossRef] [PubMed]

24. McMurray, K.M.J.; Du, X.; Brownlee, M.; Palmer, A.A. Neuronal overexpression of Glo1 or amygdalar microinjection of methylglyoxal is sufficient to regulate anxiety-like behavior in mice. Behav. Brain Res. 2016, 301, 119-123. [CrossRef] [PubMed]

25. McMurray, K.M.J.; Ramaker, M.J.; Barkley-Levenson, A.M.; Sidhu, P.S.; Elkin, P.; Reddy, M.K.; Guthrie, M.L.; Cook, J.M.; Rawal, V.H.; Arnold, L.A.; et al. Identification of a novel, fast-acting GABAergic antidepressant. Mol. Psychiatry 2018, $23,384-391$. [CrossRef]

26. Perez, C.; Barkley-Levenson, A.M.; Dick, B.L.; Glatt, P.F.; Martinez, Y.; Siegel, D.; Momper, J.D.; Palmer, A.A.; Cohen, S.M. Metal-binding pharmacophore library yields the discovery of a Glyoxalase 1 inhibitor. J. Med. Chem. 2019, 62, 1609-1625. [CrossRef]

27. McMurray, K.M.J.; Sidhu, P.S.; Cook, J.M.; Arnold, L.A.; Palmer, A.A. Genetic and pharmacological manipulation of glyoxalase 1 regulates voluntary ethanol consumption in mice. Addict. Biol. 2015, 22, 381-389. [CrossRef]

28. De Guglielmo, G.; Conlisk, D.E.; Barkley-Levenson, A.M.; Palmer, A.A.; George, O. Inhibition of Glyoxalase 1 reduces alcohol self-administration in dependent and nondependent rats. Pharm. Biochem. Behav. 2018, 167, 36-41. [CrossRef]

29. Distler, M.G.; Gorfinkle, N.; Papale, L.A.; Wuenschell, G.E.; Termini, J.; Escayg, A.; Winawer, M.R.; Palmer, A.A. Glyoxalase 1 and its substrate methylglyoxal are novel regulators of seizure susceptibility. Epilepsia 2013, 54, 649-657. [CrossRef]

30. Kumar, S.; Porcu, P.; Werner, D.F.; Matthews, D.B.; Diaz-Granados, J.L.; Helfand, R.S.; Morrow, A.L. The role of GABAA receptors in the acute and chronic effects of ethanol: A decade of progress. Psychopharmacology 2009, 205, 529-564. [CrossRef]

31. Rogawski, M.A. Update on the neurobiology of alcohol withdrawal seizures. Epilepsy Curr. 2005, 5, 225-230. [CrossRef]

32. Sachdeva, A.; Choudhary, M.; Chandra, M. Alcohol withdrawal syndrome: Benzodiazepines and beyond. J. Clin. Diagn. Res. 2015, 9, VE01-VE07. [CrossRef] [PubMed]

33. Crabbe, J.C.; Merrill, C.D.; Belknap, J.K. Effects of convulsants on handling-induced convulsions in mice selected for ethanol withdrawal severity. Brain Res. 1991, 550, 1-6. [CrossRef]

34. Goldstein, D.B.; Pal, N. Alcohol dependence produced in mice by inhalation of ethanol: Grading the withdrawal reaction. Science 1971, 172, 288-290. [CrossRef] [PubMed]

35. Martinez, J.M.; Groot, J.A.; Curtis, D.C.; Allison, C.L.; Marquardt, P.C.; Holmes, A.N.; Edwards, D.S.; Trotter, D.R.M.; Syapin, P.J.; Finn, D.A.; et al. Effective Reduction of acute ethanol withdrawal by the tetracycline derivative, tigecycline, in female and male DBA/2J mice. Alcohol. Clin. Exp. Res. 2016, 40, 2499-2505. [CrossRef] [PubMed]

36. Nipper, M.A.; Jensen, J.P.; Helms, M.L.; Ford, M.M.; Crabbe, J.C.; Rossi, D.J.; Finn, D.A. Genotype differences in sensitivity to the anticonvulsant effect of the synthetic neurosteroid ganaxolone during chronic ethanol withdrawal. Neuroscience 2019, 397, 127-137. [CrossRef] [PubMed] 
37. Perez, E.; De Biasi, M. Assessment of affective and somatic signs of ethanol withdrawal in C57BL/6J mice using a short-term ethanol treatment. Alcohol 2015, 49, 237-243. [CrossRef] [PubMed]

38. Homanics, G.E.; Le, N.Q.; Kist, F.; Mihalek, R.; Hart, A.R.; Quinlan, J.J. Ethanol tolerance and withdrawal responses in GABAA receptor alpha 6 subunit null allele mice and in inbred C57BL/6J and strain 129/SvJ mice. Alcohol. Clin. Exp. Res. 1998, 22, 259-265. [CrossRef]

39. Gorin-Meyer, R.E.; Wiren, K.M.; Tanchuck, M.A.; Long, S.L.; Yoneyama, N.; Finn, D.A. Sex differences in the effect of finasteride on acute ethanol withdrawal severity in C57BL/6J and DBA/2J mice. Neuroscience 2007, 146, 1302-1315. [CrossRef]

40. Gililland-Kaufman, K.R.; Finn, D.A. The Impact of gonadectomy and adrenalectomy on acute withdrawal severity in male and female C57BL/6J and DBA/2J mice following a single high dose of ethanol. Alcohol. Clin. Exp. Res. 2007, 31, 1846-1857. [CrossRef]

41. Becker, H.C.; Hale, R.L. Repeated episodes of ethanol withdrawal potentiate the severity of subsequent withdrawal seizures: An animal model of alcohol withdrawal "kindling". Alcohol. Clin. Exp. Res. 1993, 17, 94-98. [CrossRef]

42. Booth, B.M.; Blow, F.C. The kindling hypothesis: Further evidence from a U.S. national study of alcoholic men*. Alcohol Alcohol. 1993, 28, 593-598. [CrossRef] [PubMed]

43. McCown, T.J.; Breese, G.R. Multiple withdrawals from chronic ethanol “kindles" inferior collicular seizure activity: Evidence for kindling of seizures associated with alcoholism. Alcohol. Clin. Exp. Res. 1990, 14, 394-399. [CrossRef] [PubMed]

44. Becker, H.C.; Mulholland, P.J. Neurochemical mechanisms of alcohol withdrawal. Interv. Neuroradiol. 2014, 125, 133-156. [CrossRef]

45. Lovinger, D.M.; Roberto, M. Synaptic effects induced by alcohol. Curr. Top. Behav. Neurosci. 2010, 13, 31-86. [CrossRef]

46. Olsen, R.W.; Spigelman, I. GABAA receptor plasticity in alcohol withdrawal. In Jasper's Basic Mechanisms of the Epilepsies, 4th ed.; Noebels, J.L., Avoli, M., Rogawski, M.A., Olsen, R.W., Delgado-Escueta, A.V., Eds.; National Center for Biotechnology Information: Bethesda, MD, USA, 2012. Available online: http:/ / www.ncbi.nlm.nih.gov/books/NBK98172/ (accessed on 14 November 2020). 